\title{
Language and Cultural Analysis of Restaurant Names Take Xinxiang City Restaurant as an example
}

\author{
Xiaojun Liu \\ Xinxiang University, Xinxiang 453003, China
}

\begin{abstract}
The name of the shop as a social phenomenon, is no longer a simple business activity of a sign, it is a cultural implication. Restaurant name as a language application form, reflects the social culture. There are connotations, there are characteristics of the restaurant name can attract the attention of consumers, bring more economic benefits. From the perspective of language culture dining restaurant name, can reflect the name of the language, cultural psychology and other content. This paper takes the names of 360 restaurants in Xinxiang as the research objects, classifies them from the aspects of the phonetic characteristics, structural features, writing characteristics and cultural connotations of the restaurant name, and tries to find out the commonness and characteristics of the restaurant name and analyze its language and culture Inheritance and use.
\end{abstract}

Keywords: Food name; Xinxiang; Language features; The cultural connotation

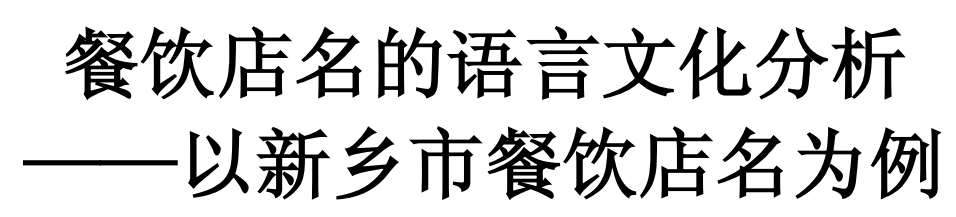

刘晓军

( 新乡学院文学院, 河南新乡453003)

摘要: 店名作为一种社会现象, 已不再是单纯的商业活动的一种标志, 更是一种文化的蕴涵。餐饮店名作为语言的一种 应用形式, 折射着社会文化。有内涵、有特色的餐饮店名可以吸引消费者的眼球, 带来更多经济效益。从语言文化角度研究 餐饮店名, 能够反映出店名的语言特征、文化心理等内容。论文以新乡市 360 家餐饮店名作为研究对象, 从餐饮店名的语音 特点、结构特点、书写特点、文化内涵等方面对其进行分类归纳, 试图发现餐饮店名的共性和特性, 分析其对语言和文化的 继承与运用。

关键词: 餐饮店名; 新乡; 语言特点; 文化内涵

中图分类号: $\mathbf{H 0 3 0}$ 文献标识码: A

引言

中国的饮食文化源远流长, 餐饮业近些年也有了突飞猛进的发展。各地饮食在长期演变中形成了众多 地方特色, 成为地域文化的一个部分。在经济文化发达的今天, 店名所起到的绝不仅仅是一个商业标识的 作用。店名就是一块活招牌, 使商家可以直接与顾客 “对话”。商家可以通过店名吸引顾客, 让顾客记住 自己, 了解自己; 通过店名招徕顾客, 向顾客推销自己, 从而获得更大的经济效益。店名是语言和文化的 一种文字体现形式, 既运用了语言和文化, 也在传播、传承着语言和文化。一个好的名称, 可以体现出一 个商家的经营理念, 蕴藏着无限的商机, 也可以折射出一个地区的语言、文化、心理等各个方面的内容。

餐饮店名作为一种鲜活的语言现象, 语料丰富, 贴近老百姓的现实生活, 可以反映出一个民族的语言 文化内涵。本文中出现的店名包括了宾馆、酒店、饭店和烘焙坊等的名称。

对于店名的分析前人已经有一些研究成果, 但目前以新乡为例研究餐饮店名还极少。本文采用实地调查与 网络搜索相结合、定量与定性相结合的方法, 通过对新乡餐饮店名的统计分析研究, 能够揭示出新乡餐饮 
店名的语言特点和店名中蕴含的历史文化, 总结出餐饮店名的基本要求和规范。

\section{1 餐饮店名的语音特点和结构特点}

\section{1 语音特点}

语音特点主要从音节方面进行分析。音节是人自然感知到的最小语音单位。在收集到的新乡餐饮店名 中, 最短的店名是由一个双音节构成的, 最长的店名是由十一个音节组成的。其中双音节的店名占比 $3.2 \%$, 三音节的店名占比 $11.7 \%$, 四音节的店名占比 $30.7 \%$, 五音节的店名占比 $13.5 \%$, 六音节的店名占比 $15.3 \%$, 七音节的店名占比 $11.4 \%$ ，八音节的店名占比 $8.5 \%$ ，九音节的店名占比 $2.1 \%$ ，十音节的店名占比 $2.5 \%$, 十一音节及以上的店名占比 $1.1 \%$ 。

可见, 三到八个音节的店名数量较多, 占了总数的 $91.1 \%$, 而双音节和九个及以上音节的店名数量明 显减少，仅占 $8.9 \%$ 。由于双音节所含的信息量相对较少，双音节店铺名被使用也较少。九音节以上的店名 信息涵盖量大但是太过于冗长而不方便记忆, 使用也较少。四音节的店名使用最多, 分布特点是以四音节 为高峰向两个方向逐渐减少。[1]

\section{2 结构特点}

从结构上看，店名一般由属名、业名、通名构成。表明所属和个性的区别性名号，可称之为属名，表 示从业类型的名称，可称之为业名，表示商业单位的通用称呼，可称之为通名。但并非所有店名都包含全 面。 ${ }^{[2]}$

新乡餐饮店名的组合形式主要有：属名+业名，如 “东北大排骨”、“晴天见神态茶饮” 等，这种组合 方式的店名最多; 属名+通名，如 “人民饭店”、“商会大酒店” 等; 业名+通名，如 “烙馍村”、“鸡公保 美食城” 等; 属名, 如 “爱蜜时代”、“慕鲜”; 业名, 如 “红润羊肉”、“茄汁面刀削面” 等; 属名+业名+ 通名，如 “牛仔芭比饮品屋”、“一期一会西点铺子” 等。

在收集到的新乡餐饮店名中, 通名主要有以下形式: 使用雅词, 如 “滋味轩”、“奇香坊”、“金玲东苑” 等; 使用常见词，如 “小胖家菜馆”、“阿郎酒店”、“逸仙居酒家” 等; 使用新词，如 “美石记”、“一生一 世吧” 等。业名主要有以下形式: 标明经营种类, 如 “海景咖啡”、“红火飞扬老汤面疮㾂”、“九街烧饼” 等; 标明地域特色, 如 “温州虹桥饭店”、“老东北野生大鱼坊”、“重庆乡下人老火锅” 等; 标明菜系特色, 如 “恋湘情”、“蜀郎轩”、“川味百城” 等; 标明制作方式, 如 “阿凡提烧烤城”、“好常来旋转涮吧”、“好 又多红炮羊肉” 等; 标明菜品属性, 如 “养生䉼坊”、“鱼季秘制烤鱼店”、“尚品时尚烘焙” 等。属名主要 有以下形式: 以称谓命名的, 如 “张亮麻辣涊”、“毛氏火锅” 等; 以地域命名的, 如 “澜海湾西餐厅”、“望 江南”、“道口烧鸡” 等; 以物品命名的，如 “橘子餐厅”、“小船儿麻辣湠”、“布丁工坊” 等; 以美好祈愿 命名的, 如 “状元红小火锅”、“多福碳锅鸡碳锅鱼”、“喜来客碳烤鱼” 等; 以制作材料命名的, 如 “鸡鱼 轩面吧”、“大盆骨”、“虾客行”等。 ${ }^{[3]}$

\section{2 餐饮店名的书写特点}

餐饮店发展至今，有悠久的历史，简单的书写形式早已不能满足店主人和顾客的审美需求以及求新创 新的心理, 出现了形式多样的书写类型。

\section{1 纯汉字类的店名}

2.1.1 使用现在通行的简化字 
这类店名在搜集到的店名是最多的，这说明简化字的使用在店名语言中占绝对优势，为广大人民所接 受。如“川人百味”、“望江南”、“岁岁羊”、“张亮麻辣烫”、“鱼派”、“虾客行”等。

\section{1.2 使用繁体字}

有些餐饮店为了吸引顾客，凸显格调，会在店名中使用一些繁体字，如：“進家門”、“蜀園餐厅”、“唐 莊香”、“火辣壹號”、“瑞可爺爺的店”等。[4]

\section{2 使用汉字和其他文字的店名}

\subsection{1 使用汉字和其他文字混合的店名}

使用汉字和其他文字混合书写的餐饮店名让人觉得耳目一新, 给人留下深刻的印象。如: “99 香辣蟹 火锅”、“60 地锅䊿”、“鄉针钭 $3 \bullet 6 \bullet 9$ 元蒸碗菜坊” 等, 是用汉字和阿拉伯数字组合而成的店名; “For-You 遇见茶饮”、“Thousand SUNNY 咖啡馆”、“圣心 DIY 手工烘焙” 等, 是使用汉字和英文字母混合书写的店名; “零夏 $1^{\circ} \mathrm{C}$ ”、“85 度 C 享甜” 等, 是使用汉字、英文字母、数字和一些特殊符号组成的店名。

\section{2 .2 使用汉字和其他文字对应的店名}

“罗蒂爸爸PaPaRoti”、“伊莎贝拉 ISALIA”、“哥德咖啡 GOOD COFFEE”等，采用纯音译的方式用中文 对应书写; “优格时刻 Yogurt time”、“泡芙时代 PUFF AGE” 等，采用半音译半意译的方式用中文对应书 写; “咖啡之翼 WING CAFE”、“橘子餐厅 Orange Restaurant”、“吃米 EAT RICE” 等，采用意译的方式用中 文对应书写。

一些店名虽然也是汉字和英文字母混合使用, 但有些英文字母却是拼音的表现形式, 如 “玉海大酒店 YU HAI DA JIU DIAN”、“火辣壹号 HUOLAYIHAO”、“后海 HOUHAI” 等。

\section{3 餐饮店名的文化内涵}

文化是一种社会历史现象，通过人们的创造活动产生，记录和传承着人类在社会历史发展过程中的各 种活动。餐饮店名作为一种语言符号，在一定程度上受到文化的影响，反映着文化。

\section{1 民族文化}

儒家文化。儒家素来重视和谐，无论是 “以和为贵”，还是 “天时地利人和”，都能体现出儒家的和谐 思想。如 “和记香辣猪手保”、“和府特色麻辣烫”, 就是对儒家 “和” 文化的继承和运用。

家族文化。“家” 在人们的心中有着举足轻重的地位, 这一点在餐饮店名上也有体现。如 “老家”、“进 家門” 和 “大家庭火锅”, 虽然是餐馆, 却给人一种家的感觉, 让人觉得温馨。受家庭观念的影响, 人们 也格外重视亲情，如表现兄弟情的“花甲兄弟”，表现姐妹情的“姐妹骨汤麻辣汤烩面”。

吉祥文化。出于对幸福、美满生活的向往，人们会创造出许许多多有着美好寓意的字词、图案等等来 祈求幸福、吉祥。如 “怡客源黄炮鸡米饭” 和 “状元红小火锅”, 通过有吉祥寓意的语言来表达希望该店 顾客多，生意红火的愿望; “福莱士” 和 “润泽会面” 则是以有吉祥意义的文字作为店名，此类字眼还有 “惠、祥、喜、好、佳、懿”等。 ${ }^{[10]}$

\section{2 地域文化}

体现当地文化。如 “鸿门公社”，借用了新乡洪门镇的名称，以所在地域为名; “科苑便民服务中心”, 因为紧挨着新乡的一所高校——河南科技学院而得名，体现出了浓厚的文化氛围; 而 “牧野乡村” 因牧野 广场和牧野大道而得名。红炮羊肉是一道发源于新乡、流行于河南的风味美食, 新乡地处北方, 冬日寒冷, 
所以吃红炮羊肉火锅已经成为御寒的利器。在新乡, 有很多经营此美食的店铺, 如 “好又多红炮羊肉”、“红 焳羊肉连锁店”等。 $[11]$

体现外地文化。如“醉巴鲜烤鱼”、“味蜀吾老火锅”，是川菜馆，用“巴”、“蜀”来表现地域特色; “老 杭帮”, “杭” 指的是杭州, 杭帮菜, 是浙江饮食文化的重要组成部分, 属于浙江菜的重要流派; “恋湘情”, “湘” 是湖南的简称，该餐馆为湘菜馆。 ${ }^{[12]}$

\section{4 结语}

作为城市语言之一的餐饮店名, 人的文化心理意识对它的产生有直接的影响, 餐饮店名又对大众的文 化素质有潜移默化的作用。本文对所调查的新乡市餐饮店名的语音特点、结构特点、书写特点、文化内涵 等方面进行了分析, 试图发现餐饮店名的共性和特性。通过调查分析发现, 在语音上, 新乡市餐饮店名以 三音节到八音节居多。在构成上, 餐饮店名有六种组合方式, 其中属名+业名和属名+通名的组合形式最多。 在书写上, 字体有繁有简, 其中以简体字居多, 另外还使用其他文字, 以使用汉字和英文字母搭配的居多。 在文化上，餐饮店名蕴含着丰富的文化信息。

另外，餐饮店名还存在一些不规范的现象，需要我们继续研究，为餐饮店名的规范提供参考。

\section{参考文献}

[1］邵垒, 章颖. 宁波餐饮店名与地域文化的社会语言学解读[J].教育教学论坛, 2016, (25) :124-125.

[2] 李卓阳. 忻州市城区餐饮行业店名语言特点分析 [J]. 忻州师范学院学报, 2014, (3) :62-64.

[3] 任志萍.中餐馆店名的语言及文化特点分析 [J]. 修辞学习, 2004, (1):72-73.

[4] 王晶. 当代餐饮店名的语言特点分析 [J]. 吉林华侨外国语学院学报, 2014, (2):64-70.

[5] 陈依苗, 孙欣. 宁波市餐饮店名的词汇分析 [J]. 探索争鸣, 2016, (5) : 174.

[6] 潘峰. 店名语用的三个原则——高校附近的店名为例 [J]. 语言文字应用, 2011, (3) : 45-54.

[7] 周智琳. 店铺名称语言文化分析一一以重庆市沙坪坝区大学城片区餐饮行业为例 [J]. 四川省社会主义学院学 报, 2015, (3):57-60.

[8]刘元娇. 济南市区餐饮店名研究[D]. 山东师范大学硕士学位论文, 2010:5-26.

[9] 黑静. 餐馆名称的语言学研究——以青岛地区为例[D]. 曲阜师范大学硕士学位论文, 2013:4-37.

[10］杨丽.上海市餐饮店名的语言学研究 [D]. 上海外国语大学硕士学位论文, 2014:5-30.

[11] 陈静.潍坊饭店名的语言文化分析 [J].滩坊社会科学, 2010, (2) : 126-127.

[12] 章晓清. 餐馆店名的语言文化解析一一以广州市天河区上社餐馆名为例 [J]. 广东技术师范学院学报（社会科 学), 2010, (3):92-95.

\section{References}

[1] Shao Lei, Zhang Ying: "A Social Linguistic Interpretation of Ningbo Restaurant and Regional Culture” [J]. Education and Teaching Forum, (2016), No.25, p.124-125 (in Chinese)

[2] Li Zhuo-yang: "An Analysis of the Language Characteristics of the Restaurant and Restaurant Industry in Xinzhou City”[J]. Journal of Xinzhou Teachers College,(2014), No.3, p.62-64 (in Chinese)

[3] Ren Zhi-ping: “An Analysis of the Language and Cultural Characteristics of Chinese Restaurant” [J]. Rhetoric learning, (2004), No.1, p.72-73 (in Chinese)

[4] Wang Jing: "An Analysis of the Language Features of Contemporary Catering" [J]. Journal of Jilin University of Foreign Languages, (2014), No.2, p.64-70 (in Chinese)

[5] Chen Yi-miao, Sun Xin: "Lexical Analysis of Restaurant Names in Ningbo City" [J]. To explore the contention, (2016), No.5, 
p. 174(in Chinese)

[6] Pan Feng: "Lexical Analysis of Restaurant Names in Ningbo City" [J]. Applied Linguistics, (2011), No.3, p. 45-54 (in Chinese)

[7] Zhou Zhi-lin: "Shop name language culture analysis- Taking the Catering Industry in Shapingba District of Daqing City as an Example"[J]. Journal of Sichuan College of Socialism, (2015), No.3, p. 57-60 (in Chinese)

[8] Liu Yuan-jiao: "Study on the Restaurant Name of Jinan City" [D]. Master's Degree Thesis of Shandong Normal University, (2010), p. 5-26 (in Chinese)

[9] Hei Jing: "A linguistic study of the name of the restaurant- Taking Qingdao as an example”[D]. Qufu Normal University Master's Degree Thesis, (2013), p. 4-37 (in Chinese)

[10] Yang Li: "A Study on the Linguistics of Shanghai Restaurant" [D]. Master's Degree Thesis of Shanghai Foreign Studies University, (2014), p. 5-30 (in Chinese)

[11] Chen Jing: "An Analysis of the Language and Culture of Weifang Hotel” [J]. Weifang Social Science, (2010, No.2, p. 126-127 (in Chinese)

[12] Zhang Xiao-qing: "On the Language and Culture of Restaurant- A Case Study of Shangshe Restaurant in Tianhe District, Guangzhou City” [J]. Journal of Guangdong Polytechnic Normal University (Social Science), (2010), No.3, p. $92-95$ (in Chinese) 